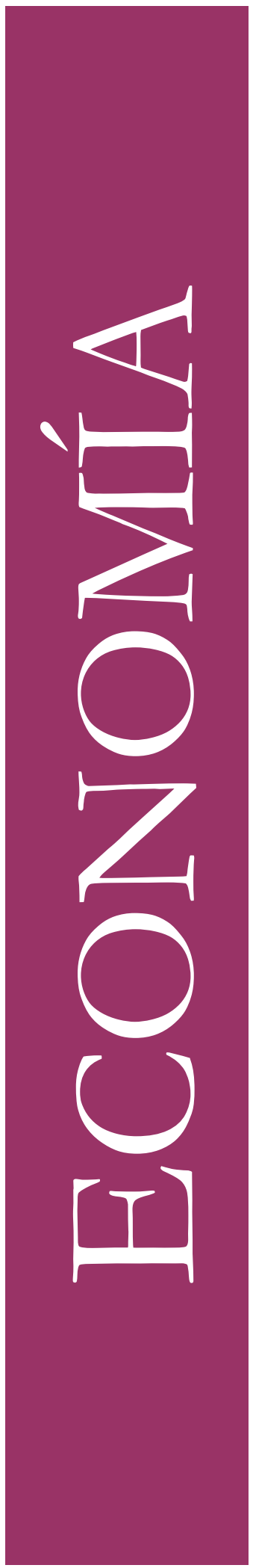

SERIE DOCUMENTOS

DOCUMENTOS

DE

TRABAJO

No. 12 /Marzo 2007

Financial protection for the poor in Colombia: the effects of a subsidized health insurance scheme

Ramón Castaño

Andrés Zambrano

(Documento de Trabajo, citar con autorización del autor)

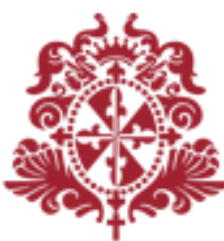

UNIVERSIDAD DEL ROSARIO 


\title{
Financial protection for the poor in Colombia: the effects of a subsidized health insurance scheme ${ }^{\bullet}$
}

\author{
Ramón Castaño \\ ramon.castano@urosario.edu.co \\ Andrès Zambrano \\ jzambran@urosario.edu.co
}

\begin{abstract}
Financial protection is one of the objectives of health systems, which protects poor households from falling into poverty as a result of health care related expenses. Expanding prepayment schemes to the poor is difficult in developing countries because labor is largely informal. Providing health care free-at-point-of-service does not adequately target spending on the poorest, but occupation- or community-based schemes have also inherent limitations to achieve universal coverage. Colombia adopted a government-subsidized health insurance scheme (SHI) strategy. The political debate about increasing SHI enrollment needs evidence about the effectiveness of this scheme regarding financial protection. This study runs a four-part model to estimate the effect of SHI on out-of-pocket expenses by the poor that are currently uninsured, if they were enrolled in the SHI. The results show a $43 \%$ and 50\% reduction in expenses at Bogotá and national level respectively, which confirms the effectiveness of SHI as a financial protection tool.
\end{abstract}

Key words: Financial protection, subsidized insurance, out-of-pocket expenses, Colombia

Running title: Financial protection by subsidized insurance

\section{Introduction}

One of the health system's goals that is pointed out by the World Health Organization is to guarantee an equitable contribution to the financing of the system (WHO, 2000). This entails the implementation of a progressive tax-based collection system (either general taxes or payroll taxes) independent of individual risk, and an adequate insurance scheme that isolates households of the financial negative impacts of disease or trauma. Financial protection thus emerges as one of the key functions of health systems as household's health care expenses are major causes of impoverishment (Wagstaff and Van Doorslaer (2003), Preker (2002)). For example, in rural China, the collapse of cooperatives after the marketizing reforms of the eighties left households fully responsible for health-related expenses. Consequently, the number of households that fall below the poverty line

\footnotetext{
- Las opiniones aquí expresadas son responsabilidad de los autores y por lo tanto no deben ser interpretadas como propias de la Facultad de Economía ni de la Universidad del Rosario
} 
increased by $44 \%$ (Liu, 2004). Hsiao (2002) reports that the most important cause of household's failure to pay back debts to the Grameen Bank in Bangladesh, was impoverishment due to health-related expenses.

One key strategy to improve financial protection is to expand prepayment schemes, and to enlarge the pooling ability of these schemes to the highest possible level (WHO, 2000). This allows to disperse large risks without threatening financial viability of the whole insurance scheme. However, insurance schemes in developing countries are difficult to implement because a large share of the economy is informal, so that the operation of a social insurance scheme or a large voluntary insurance scheme is difficult to operate. Expectations in the seventies that labor will become more formal, have been frustrated in the nineties to recognize that informality has increased, making social security coverage to stall (Unni and Rani, 2001).

This puts a difficult challenge to achieve financial protection for the poor, because they are precisely the ones in the informal economy, and the more difficult to reach through social security schemes. A traditional approach has been to offer services free-at-point-of-service, through a supply-side subsidized network of public providers. This approach is based on the assumption that these services will be self-targeted, which allows the poor to be financially protected. However, self-targeting has been shown to fail to reach the poor, particularly regarding intermediate and high complexity health care services (Gwatkin, 2005).

An alternative approach to supply-side subsidized services has been the emergence of community-based insurance schemes. These schemes are based on community links rather than on employer-employee relationships, because the latter are very informal and discontinuous. Given that poor households spend a large share of their income in healthrelated events, efforts should be made to redirect these outlays towards prepayment schemes to improve efficiency in purchasing services (Hsiao, 2002). In a different sense, Gillion (1999) proposes to expand social security to the informal sector by targeting the informal uninsured through their occupational links.

Either occupation-based or community-based, insurance schemes with informal population face other types of challenges, mainly adverse selection, provider capture, and lack of large-scale pooling. Lack of managerial capacity to perform enrolment, collections, purchasing and an adequate handling of financial resources, reinforce the weaknesses of these schemes (Preker (2002), Jakab and Krishnan (2002)).

A third approach is to create a government-based insurance scheme that enrolls the poor at no cost or with a partial contribution to the premium. The insurance scheme is operated by insurers who contract with providers as any other third party payer. This is the scheme of the Medicaid in the United States, and more specifically the Medicaid HMO scheme. However, a tax-credit strategy to reduce the insurance price and encourage the uninsured to enroll has limited effect given the low price elasticity of insurance among the target group (Gruber and Poterba, 1993). Increased government funding to expand coverage has also had limited effect (Madden et al, 1995). The reduced effect of these strategies is explained by Chernew et al (1997) by the presence of safety net hospitals providing free care, which 
work as a substitute for insurance. Craig (1991) also argues that costs related to information, processing, and stigma; prevent poor households from taking up a subsidized scheme.

Experiences in developing countries have also been analyzed, although less thoroughly. The health card scheme in Thailand is a good case in point (Supakankunti, 2000). This was a partial subsidy to the premium, that was implemented by the government to increase enrollment among the poor. It is likely that the participation of the government has encouraged poor household's participation, but adverse selection still pervaded the scheme.

\section{The Colombian subsidized health insurance scheme}

Colombia launched a major health sector reform in 1993, aimed at universal coverage. However, its large share of informal economy, which in 2003 was 61\% (DANE, 2003), stands as a major obstacle to expand employment-based social insurance schemes. Thus, a subsidized health insurance (SHI) scheme was created to enroll informal workers and the indigent. The scheme is financed via a $1 \%$ payroll tax paid by formal workers plus a share of general tax revenues. The municipal authorities apply a proxy-means test to identify the eligible poor or informal workers, and the government transfers the necessary funds to enroll them in the scheme. However, with only few exceptions, municipalities have higher number of eligible poor than resources available to enroll them in the SHI, so they must enroll the poorest of the poor according to the score yielded by the proxy-means test. Once the municipality has selected the group of eligible poor to be enrolled, it opens a competitive process through which the selected eligible choose the insurer of their preference among the options that have been previously authorized to operate the SHI. Then, the municipality transfers to the insurer the corresponding premium and the insurer is responsible for providing the contents of the benefit package that has been defined by the national authority of the health social security system. This benefit package is not as comprehensive as the package of the employment-based insurance, because the resources for financing the premiums are smaller. Those interventions not included in the package are provided by the public network and are not the responsibility of the SHI insurers.

Although in principle the 1993 reform aimed at enrolling $70 \%$ of the population in the employment-based scheme and only the remainder 30\% in the SHI (roughly 30 million and 13 million enrollees respectively, by 2005), the high proportion of informal workers has made impossible to reach the $70 \%$ goal for the employment-based scheme. By 2005 , the scheme hardly covered 16 million enrollees, falling short of its 30 million expected enrollment. The government has tried to bridge this gap by expanding coverage through the SHI, which by 2005 covered about 16 million enrollees plus 1.8 million additional enrollees covered with a very limited subsidized scheme.

The government and the legislative bodies have made several proposals to increase coverage by the SHI, all of which depend on available resources and its long-term sustainability. One relevant question for the policy debate regards the positive effects of insurance in terms of financial protection and access to health care services. Many critics of the reform have pointed out that insurers in the SHI create access barriers to enrollees, and indeed have proposed the abolition of the SHI. However, previous empirical evidence 
suggests that this scheme reduces financial barriers to access (Yepes and Ramírez, 2003). It has also been shown that insurance status has a strong positive effect on access (Restrepo et al, 2005), and that enrollees in the SHI have lower out-of-pocket (OOP) spending as compared to the uninsured (O’Meara et al, 2003).

Accordingly, this study aimed at estimating the effect of enrollment in the SHI on OOP expenses as a means of testing the potential for financial protection of the SHI. A large effect in this regard will be a strong justification for expanding insurance coverage to the poor.

\section{Methodology}

A cross sectional national level LSMS-type survey was used to test the reduction in OOP expenses among the poor uninsured. The survey was carried out during the second half of 2003, and is representative at the national level, and it is also representative at the local level for Bogotá, the capital of Colombia. The survey collects information, among others, on household's income, expenses, and health care consumption. This latter topic includes information on OOP expenses related to the last contact with a health care provider within the previous month, and related to inpatient expenses during the last year. The survey allows to identify those enrolled in the employment-based insurance scheme, and those enrolled in the SHI. The remainder of the sample, the uninsured, had to be split into those who were eligible for SHI and those who were not. For this purpose, the proxy-means test score was applied because the survey includes the same information that is used for the application of the test. It made possible to separate the uninsured into the six categories of the test, and those included in the lower two categories were considered as poor uninsured, whereas the rest were considered non-poor uninsured. This analysis focuses on the uninsured poor.

A four-part model was used to estimate the coefficients of the determinants of OOP expenses both on outpatient and inpatient care. The model was specified as follows:

- $\operatorname{Pr}\left(M E D_{i}>0\right)=\Phi\left(x_{i} \gamma_{1}\right)$

- $\operatorname{Pr}\left(I N P_{i}>0 \mid M E D_{i}>0\right)=\Phi\left(x_{i} \gamma_{2}\right)$

- $\log \left(M E D_{i} \mid M E D_{i}>0, I N P_{i}=0\right)=x_{i} \gamma_{3}+v_{i}$

- $\log \left(M E D_{i} \mid I N P_{i}>0\right)=x_{i} \gamma_{4}+w_{i}$

Where MED is OOP expenses during the last year and INP OOP expenses incurred on inpatient care only, during the last year. Equations (1) and (2) are logit models, where the dependent variable equals 1 if individual had positive OOP and 0 otherwise.

Equations (3) and (4) are loglinear models where the dependent variable is the log of OOP. Equation (3) refers to those who had any OOP $>0$ and equation (4) refers to those who had inpatient $\mathrm{OOP}>0$, given that they had any OOP $>0$. Equations (3) and (4) were estimated by ordinary least squares. $v_{i}$ and $w_{i}$ are the error terms of equations (3) y (4), and 
$E\left(v_{i}\right)=E\left(w_{i}\right)=0$. Given the highly skewed distribution of health OOP expenses, the error terms cannot be assumed to have a normal distribution. This requires the use of the smearing estimate proposed by Duan (1983), which is the average of the exponentiated error terms:

$$
\varphi_{j}=\sum_{i} \exp \left(\varepsilon_{i}\right) / n_{j}
$$

Accordingly, the expected OOP expenses can be estimated as:

$\mathrm{E}(\mathrm{OOP})=p_{i}\left[\left(1-\pi_{i}\right) \exp \left(x_{i} \gamma_{3}\right) \varphi_{3}+\pi_{i} \exp \left(x_{i} \gamma_{4}\right) \varphi_{4}\right]$

Where $p_{i}$ is the probability to have any OOP $>0,{ }{ }_{i}$ is the probability to have any inpatient OOP $>0, \quad \exp \left(x_{i} \gamma_{3}\right) \varphi_{3}$ is the estimation of OOP given no inpatient expenses, and $\exp \left(x_{i} \gamma_{4}\right) \varphi_{4}$ is the estimation of inpatient-related OOP.

The variables on the right-hand side of the equations were:

- Self-reported health status: it is a four-category variable (excelent, good, fair, poor) that was aggregated into two categories. The excluded category is the one that aggregates fair and poor.

- Chronic disease, where 1=presence of chronic disease, 0 otherwise.

- Age and gender, expressed either in seven age-gender categories or separately as a continuous variable (age) and as a dichotomous variable (gender); choice of one or the other depended on which fits best in the model.

- Household's per-capita income, estimated by overall per-capita expenditures, according to Ramírez et al (2005)

- Number of household members.

- Educational level of the most highly educated member of household.

- Urban/rural location of household (for national estimations).

- Local area in Bogotá (for Bogotá-only estimations).

t-tests were run for statistical significance, Wald tests for significance of categorical variables and for the overall model. The software used for the analysis was Stata 8.0.

Once estimated, the four-part models were "recycled", i.e., the coefficients obtained in the estimations with the insured population, were applied to the poor-uninsured. This allows to estimate the reduction in OOP expenses these individuals would face were they enrolled in the SHI.

\section{Results}

1. Equation (1): the probability of having any OOP $>0$. 
Table 1 shows the coefficients for equation (1) among those enrolled in the SHI, both for the whole country sample and for Bogota only. Poor health status, the presence of chronic conditions, age and higher income are statistically significant as predictors of OOP $>0$. Regional differences are significant at the country level but not at the Bogota level (excluded from the model). The coefficients for the poor-uninsured are shown in table 2, and reflect the same pattern observed in table 1, except for the fact that differences among local areas in Bogota are significant.

2. Equation (2): the probability of having inpatient $\mathrm{OOP}>0$, given any $\mathrm{OOP}>0$.

Table 3 shows the coefficients for equation (2) among those enrolled in the SHI. Selfreported health status shows non-significant effect for both samples, but age and the presence of chronic condition does. Income has significant effect only in the national sample, whereas education does only in the Bogota sample. Local area differences in Bogota had no statistically significant effect. Table 4 shows the coefficients among the poor-uninsured. Self-reported health status has significant effect in the Bogota sample but the effect of chronic conditions and age is non-significant. Regional differences at the national level and local area differences in Bogota showed a non-significant effect. Income was non-significant in the Bogota sample.

\section{Equation (3): Expected expenses for those having any OOP $>0$}

Table 6 shows the OLS-predicted coefficients for equation (3), for those enrolled in the SHI. While age has no statistically significant effect at the national level but it does at the Bogota level, the effect of local area differences in Bogota is significant but the regional differences at the national level are not. For the poor uninsured, table 6 shows that age has no significant effect in Bogota, whereas educational status has no effect at the country level.

4. Equation (4): Expected expenses for those having inpatient $\mathrm{OOP}>0$, given any OOP $>0$.

Table 8 shows the OLS-predicted coefficients for equation (4), for those enrolled in the SHI. Although the effect of regional differences were statistically significant for the country sample, local area differences were only significant at an $\alpha$ of $10 \%$. Gender was nonsignificant for an $\alpha$ of 5\%, and age and chronic disease were only significant for the national sample. For the poor-uninsured population, shown in table 8, self-reported health status and age-gender categories are nonsignificant for Bogotá, and regional differences were significant at the country level but local area differences for Bogotá were not.

5. Recycling: the effect of enrollment in the SHI for the poor-uninsured, on OOP

Graph 1 shows the expected monthly OOP expenses for any type of health care among the poor-uninsured according to the four-part model estimation, and the expenses they would face were they enrolled in the SHI, according to the "recycled" model using the coefficients

of the model for those enrolled in the SHI. It is clear that enrolling all the Colombian poor- 
uninsured in the SHI scheme would reduce their OOP expenses by more than $50 \%$, and in the case of Bogota this reduction would be $43 \%$. Given the high probability of falling into poverty due to health care related expenses, the SHI scheme seems an effective tool to provide financial protection to poor households.

\section{Discussion}

According to graph 1, it is evident that the SHI would drastically reduce OOP expenses by poor households if they were enrolled in this scheme. Even though the benefit package if the SHI excludes secondary and tertiary care, and it only covers primary care and high-cost conditions, the reduction in OOP expenses makes it a worth pursuing strategy to provide financial protection. Obviously this protection would be much better if these poor uninsured were enrolled in the employment-based scheme. However, available resources would not be large enough to pay the corresponding premium for this scheme (CP\$ 386.000 for 2006), which is $80 \%$ above the premium for the SHI scheme (CP\$ 215.000 for 2006). On the contrary, resources available are more likely to increase insurance coverage by enrolling the poor uninsured to the SHI. An additional reason for not enrolling the poor uninsured in the employment-based scheme is that it would be a disincentive for those formal workers that are currently enrolled in this scheme. This has been previously pointed out by Gruber (2003), who underscores the crowding-out effect that a full subsidy to a comprehensive package would have over insurance bought by employers in the US.

Achieving universal health insurance coverage is a big challenge for Colombia about which one cannot be very optimistic. Increasing enrollment in the employment-based scheme would take costly efforts towards small firms and self-employed workers, not only to enforce enrollment, but also to enforce the payment of payroll taxes based on the real salary of the worker. In addition, such enforcement would have a negative effect on formal employment, as employers in these firms would prefer to shift to informality than face the costs of paying all the taxes and contributions. Thus, the country has to achieve a delicate balance between formal employment and enrollment in the employment-based health insurance scheme.

So it is inevitable to accept the current levels of enrollment in the employment-based scheme (about 37\% of the population) as exogenous, varying only with the dynamics of the labor markets. The alternative to increase coverage is to enroll more poor-uninsured in the SHI scheme. However, given that if an individual is enrolled today the government has to make sure it will have the money to pay the premium for the coming years, long-term resource constraints are the key to expand coverage. Some of the proposals discussed in the legislative bodies have considered that the payroll tax formal employees pay to the SHI is increased from $1 \%$ to $2 \%$ as a source of fresh resources. However, this is a risky decision, as it has been shown that a -0.4 price elasticity of labor (Kugler and Kugler 2002) would cause a further decrease in employment, let alone the substitution effect with informal labor. Certainly, this trade-off is worth analyzing carefully, before embracing a proposal that has been enthusiastically promoted by politicians narrowly sensitive to the health sector. 
But even if the country had the necessary resources to enroll the poor-uninsured in the SHI, it would be likely that not all the eligible will decide to enroll. On the one hand, according to Craig (1991), the responses of target populations to the offer of a subsidy, the so-called take-up behavior, predict that some households will prefer not to enroll, due to information, processing, and stigma costs. A second factor that discourages take-up is the presence of a perfect substitute to insurance, namely, the public hospital network. If people can show up at the local hospital when sick, and will receive care at minimum or no cost, why bother about taking all the information and processing costs of taking-up the subsidy? And lastly, there is a small percentage of the population that dislikes the idea of insurance, no matter it is fully subsidized (Chernew et al, 1997). In a country like Colombia, with strong security concerns, it is not uncommon that people do not want to be identified, and some of them prefer to frequently change their places of residence to avoid personal risks.

These factors explaining non-take-up behavior are quite relevant in Bogota, the capital city of Colombia. Whereas the city has the highest coverage of the poor through SHI enrollment, recent efforts to increase coverage have been frustrated and thousands of available slots are not taken-up by those eligible. Perhaps the eligible population that was willing to take-up the subsidy has been exhausted and additional efforts will have to be taken to have enrollment increase. This is not the case however for the rest of the country.

One plausible explanation for the frustrated efforts to increase coverage has to do with payment incentives to providers. First, the local health authority pays public hospitals on a per-case basis for care provided to the uninsured. Second, insurers in the SHI negotiate capitated contracts with public hospitals. So, the hospital will be better off if it maximizes the outputs to be billed to the health authority at the expense of minimizing output to SHI enrollees. It can also be said that insurers in the SHI scheme have an incentive to put access barriers, given the incentives inherent in the insurance scheme. As hospital users realize differences in access, voice spreads about the access barriers faced by SHI enrollees, and hence the apathetic reaction by the target population.

A different alternative would be to focus subsidized insurance on high-risk individuals, specifically those with chronic conditions. Given that their expected loss ratios are much higher than the rest of the population, and their higher probability to incur impoverishing expenses, it makes sense to enroll these individuals with a comprehensive benefit package. However, this alternative poses additional challenges regarding selection incentives and the estimation of an actuarially fair premium. 


\section{Conclusion}

This study confirms the hypothesis that health insurance is effective at providing financial protection for poor households. In the particular case of the SHI scheme for the poor in Colombia, if coverage is expanded to enroll the poor-uninsured, out-of-pocket expenses would be reduced in about 50\% at the country level, and at least $43 \%$ at the Bogota level. This is a strong justification for expanding coverage of the SHI scheme in Colombia. 


\section{Authorship:}

R Castano conceived and designed the study, prepared the manuscript, and participated in data interpretation. No conflict of interests are declared.

A Zambrano run the data analysis and interpretation, and participated in the preparation and revision of the manuscript. No conflict of interests are declared. 


\section{References}

Chernew M, Frick K, McLaughlin CG. 1997. The demand for health insurance coverage by low-income workers: can reduced premiums achieve full coverage? Health Services Research. 32(4):453-70.

Craig P. 1991. Costs and benefits: a review on take-up of income-related benefits. Journal of Social Policy 20(4):537-65.

DANE. 2003. Encuesta continua de hogares. Resultados hasta junio/2003. Boletín de prensa

Duan N, Manning WG, Morris CN, Newhouse JP. 1983. A comparison of alternative models for the demand for health care. Journal of Business \& Economic Statistics 1:11526.

Gillion C. 1999. Preface. In: VanGinneken W (ed). Social security for the excluded majority: Case studies of developing countries.Geneva: International Labor Office, .

Gruber J. 2003. Evaluating alternative approaches to incremental health insurance expansion. American Economic Review 93(2):271:276.

Gruber J, Poterba J. 1993. Tax incentives and the decision to purchase health insurance from the self-employed. NBER Working Paper \# 4435.

Gwatkin DR. 2005. From whom to buy? Are free government health services the best way to reach the poor? In: Preker AS and Langenbrunner JC (ed). Spending wisely. Washington: The World Bank, 47-60.

Hsiao WC. 2002. Experience of community health financing in the Asian Region. In: Comission on Macroeconomics and Health (ed). Health care financing for rural and lowincome populations. Geneva: WHO. 
Jakab M, Krishnan C. 2002. Review of the strengths and weaknesses of community financing. In: Comission on Macroeconomics and Health (ed). Health care financing for rural and low-income populations. Geneva: WHO.

Kugler, A., and M. Kugler. 2002. Effects of Payroll Taxes on Employment and Wages: Evidence form the Columbian Social Security Reform. Center for Research on Economic Development and Policy Reform Working Papers, 134.

Liu Y. 2004. Development of the rural health insurance system in China. Health Policy and Planning 19(3):159-165.

Madden CW, Cheadle A, Diehr P, Martin DP, Patrick DL, Skillman SM. 1995. Voluntary public health insurance for low-income families: the decision to enroll. Journal of Health Politics, Policy and Law. 20(4):955-72.

O’Meara G, Ruiz F, Amaya JL (2003). Impacto del aseguramiento sobre el uso y gasto de los servicios de salud en Colombia, 2002. Bogotá: CEJA.

Preker AS. 2002. Health care financing for rural and low-income populations. In: Comission on Macroeconomics and Health (ed). Health care financing for rural and lowincome populations. Geneva: WHO.

Ramírez M, Muñoz M,Zambrano A. 2005. El gasto de los hogares colombianos según las encuestas de calidad de vida: magnitud, composición y distribución. Borrador de investigación Facultad de Economía - Universidad del Rosario.

Restrepo J, Zambrano A, Vélez M, Ramírez M. 2005. Health insurance as a strategy for access: streamlined facts of the Colombian health care reform. Paper presented at 5th World iHEA Congress, Barcelona, Tuesday July 12. Unpublished document.

Supakankunti S. 2000. Future prospects of voluntary health insurance in Thailand. Health Policy and Planning 15(1):85-94. 
Unni J, Rani U. 2001. Social protection for informal workers. The Indian Journal of Labor Economics 44(4):561-75.

Wagstaff A, Van Doorslaer E. 2003. Catastrophe and impoverishment in paying for health care: with applications to Vietnam 1993-1998. Health Economics 12(11):921-34.

WHO. 2000. The World Health Report. Geneva: World Health Organization 


\section{Acknowledgements}

We thank Colciencias for financial support for this project. We also thank Francisco Yepes and Manuel Ramírez for their support and criticism during the execution of this research project and the preparation of this manuscript. 
Table 1. Log-odds for the probability of having any OOP $>0$ among SHI enrollees.

\begin{tabular}{|c|c|c|c|c|}
\hline & \multicolumn{2}{|c|}{ NATIONAL } & \multicolumn{2}{|c|}{ BOGOTA } \\
\hline & Coeff. & $\mathrm{t}$ & Coeff. & $\mathrm{t}$ \\
\hline Self-reported health status & & & & \\
\hline Fair & -1.022 & $-8.44 * * *$ & -1.131 & $-6.18^{* * *}$ \\
\hline Good & -2.046 & $-14.46 * * *$ & -2.047 & $-9.82 * * *$ \\
\hline Very Good & -2.792 & $-9.58 * * *$ & -2.015 & $-5.46 * * *$ \\
\hline Wald test & \multicolumn{2}{|c|}{$86.76^{* * *}$} & \multicolumn{2}{|c|}{$34.81 * * *$} \\
\hline Chronic disease & 0.405 & $4.51^{* * *}$ & 0.444 & $3.27 * * *$ \\
\hline Age-gender categories & & & & \\
\hline $1-4$ & -0.063 & -0.21 & 0.078 & 0.200 \\
\hline $5-14$ & -0.872 & $-3.04 * * *$ & -1.056 & $-2.73 * * *$ \\
\hline 15-44 male & -0.697 & $-2.43^{* *}$ & -0.777 & $-2.02 * *$ \\
\hline $15-44$ female & -0.395 & -1.400 & -0.513 & -1.370 \\
\hline $45-59$ & -0.691 & $-2.37 * *$ & -0.575 & -1.490 \\
\hline $60+$ & -0.666 & $-2.24 * *$ & -0.542 & -1.390 \\
\hline Wald test & \multicolumn{2}{|l|}{$7.99 * * *$} & \multicolumn{2}{|l|}{$5.32 * * *$} \\
\hline Log income per-capita & 0.525 & $9.4 * * *$ & 0.431 & $4.69 * * *$ \\
\hline Education & & & & \\
\hline Primary & 0.433 & $1.82 *$ & & \\
\hline Secondary & 0.702 & $2.95^{* * *}$ & & \\
\hline Post-secondary & 0.466 & $1.74 *$ & & \\
\hline Wald test & \multicolumn{2}{|l|}{$6.24 * * *$} & & \\
\hline \multicolumn{5}{|l|}{ Region } \\
\hline Oriental & -0.214 & -1.640 & & \\
\hline Central & 0.173 & 1.320 & & \\
\hline Pacífico & 0.194 & $1.69 *$ & & \\
\hline Bogotá & -0.266 & $-2.33^{* *}$ & & \\
\hline Antioquia & 0.266 & $1.95^{*}$ & & \\
\hline Valle & 0.092 & 0.590 & & \\
\hline San Andrés & -1.123 & $-3.48 * * *$ & & \\
\hline Orinoquia & 0.447 & $2.61^{* * *}$ & & \\
\hline Wald test & \multicolumn{2}{|l|}{$8.67 * * *$} & & \\
\hline Constant & -6.933 & $-9.36^{* * *}$ & -5.412 & $-4.7 * * *$ \\
\hline $\mathrm{N}$ & \multicolumn{2}{|l|}{17823} & \multicolumn{2}{|l|}{6590} \\
\hline General Wald test & \multicolumn{2}{|l|}{$29.85 * * *$} & \multicolumn{2}{|c|}{$24.68 * * *$} \\
\hline
\end{tabular}


Table 2. Log-odds for the probability of having any OOP $>0$ among poor-uninsured.

\begin{tabular}{|c|c|c|c|c|}
\hline & \multicolumn{2}{|c|}{ NATIONAL } & \multicolumn{2}{|c|}{ BOGOTA } \\
\hline & Coeff. & $\mathrm{t}$ & Coeff. & $\mathrm{t}$ \\
\hline Self-reported health status & & & & \\
\hline Fair & -0.951 & $-4.32 * * *$ & -0.419 & $-1.7^{*}$ \\
\hline Good & -1.939 & $-8.19 * * *$ & -1.654 & $-6.45 * * *$ \\
\hline Very Good & -1.504 & $-4.07 * * *$ & -2.218 & $-5.22 * * *$ \\
\hline Wald test & \multicolumn{2}{|c|}{$30.80 * * *$} & \multicolumn{2}{|c|}{$32.76 * * *$} \\
\hline Chronic disease & 0.674 & $4.17 * * *$ & 0.563 & $3.34 * * *$ \\
\hline Age-gender categories & & & & \\
\hline $1-4$ & -0.557 & $-1.7 *$ & 0.408 & 1.100 \\
\hline $5-14$ & -1.257 & $-4.03 * * *$ & -0.370 & -1.030 \\
\hline $15-44$ male & -1.114 & $-3.51^{* * *}$ & -0.933 & $-2.57 * *$ \\
\hline $15-44$ female & -0.581 & $-1.91 * *$ & -0.330 & -0.930 \\
\hline $45-59$ & -1.109 & $-3.31 * * *$ & -0.882 & $-2.28 * *$ \\
\hline $60+$ & -1.491 & $-4.1 * * *$ & -1.308 & $-2.93 * * *$ \\
\hline Wald test & \multicolumn{2}{|c|}{$7.26 * * *$} & \multicolumn{2}{|c|}{$8.43^{* * *}$} \\
\hline Log income per-capita & 0.531 & $5.55 * * *$ & 0.246 & $2.14^{* *}$ \\
\hline Rural & -0.620 & $-3 * * *$ & & \\
\hline Region & & & & \\
\hline Oriental & 0.175 & 0.820 & & \\
\hline Central & -0.242 & -1.210 & & \\
\hline Pacífico & 0.061 & 0.360 & & \\
\hline Bogotá & -0.463 & $-2.96 * * *$ & & \\
\hline Antioquia & -0.374 & -1.480 & & \\
\hline Valle & -0.118 & -0.580 & & \\
\hline San Andrés & -0.896 & -1.460 & & \\
\hline Orinoquia & -0.355 & -1.400 & & \\
\hline Wald test & $3.26 * *$ & & & \\
\hline Local Area & & & & \\
\hline Chapinero & & & -2.493 & $-2.27 * *$ \\
\hline Santa Fe & & & -0.967 & $-2.75 * * *$ \\
\hline San Cristóbal & & & -1.661 & $-4.81 * * *$ \\
\hline Usme & & & -1.072 & $-3.31 * * *$ \\
\hline Tunjuelito & & & -0.619 & $-1.94 *$ \\
\hline Bosa & & & -1.012 & $-3.1 * * *$ \\
\hline Kennedy & & & -0.657 & $-1.94^{*}$ \\
\hline Fontibon & & & -1.142 & $-3.11^{* * *}$ \\
\hline Engativa & & & -1.035 & $-2.68 * * *$ \\
\hline Suba & & & -0.407 & -1.160 \\
\hline Barrios Unidos & & & -1.185 & $-3.05 * * *$ \\
\hline Teusaquillo & & & -0.730 & -1.080 \\
\hline
\end{tabular}




\begin{tabular}{|l|l|ll|} 
Martires & & -2.055 & $-5.2 * * *$ \\
Antonio Nariño & & -0.996 & $-2.92 * * *$ \\
Puente Aranda & & -0.873 & $-2.26 * *$ \\
Candelaria & & -1.474 & $-3.46 * * *$ \\
Rafael Uribe & & -1.378 & $-4.15 * * *$ \\
Ciudad Bolívar & & -1.048 & $-3.24 * * *$ \\
Wald test & & $3.36 * * *$ \\
\hline Constant & $-5.830 \quad-5.03 * * *$ & -2.585 & $-1.75 *$ \\
\hline N & 8481 & 4866 \\
General Wald test & $12.66 * * *$ & $7.30 * * *$ \\
\hline
\end{tabular}

${ }^{*} p<0.1{ }^{* \star} p<0.05^{* \star *} p<0.01$ 
Table 3. Log-odds for inpatient OOP $>0$ given any OOP >0, among SHI enrollees.

\begin{tabular}{|c|c|c|c|c|}
\hline & \multicolumn{2}{|c|}{ NATIONAL } & \multicolumn{2}{|c|}{ BOGOTA } \\
\hline & Coeff. & $\mathrm{t}$ & Coeff. & $\mathrm{t}$ \\
\hline Chronic disease & 0.315 & $2.15^{* *}$ & 0.424 & $1.86^{*}$ \\
\hline Age & 0.007 & $2.4^{* *}$ & 0.010 & $2.17 * *$ \\
\hline Log income per-capita & -0.324 & $-3.22 * * *$ & & \\
\hline Education & & & & \\
\hline Primary & & & 2.095 & $2.44 * *$ \\
\hline Secondary & & & 1.635 & $1.94 *$ \\
\hline Post-secondary & & & 1.446 & 1.65 \\
\hline Wald test & & & $2.49 *$ & \\
\hline \# household members & & & 0.176 & $3.07 * * *$ \\
\hline Region & & & & \\
\hline Oriental & 0.259 & 1.1 & & \\
\hline Central & 0.473 & $1.97 * *$ & & \\
\hline Pacífico & -0.330 & -1.54 & & \\
\hline Bogotá & 0.397 & $1.92 *$ & & \\
\hline Antioquia & -0.237 & -0.94 & & \\
\hline Valle & -0.221 & -0.77 & & \\
\hline San Andrés & 0.805 & 1.27 & & \\
\hline Orinoquia & 0.444 & 1.44 & & \\
\hline Wald test & $4.05^{* * *}$ & & & \\
\hline Constant & 3.165 & $2.66 * * *$ & -2.987 & $-3.41 * * *$ \\
\hline $\mathrm{N}$ & 1926 & & 615 & \\
\hline General Wald test & $4.50 * * *$ & & $3.70^{* * *}$ & \\
\hline
\end{tabular}

${ }^{*} p<0.1{ }^{* *} p<0.05^{* * *} p<0.01$ 
Table 4. Log-odds for inpatient $\mathrm{OOP}>0$ given any $\mathrm{OOP}>0$, among poor-uninsured

\begin{tabular}{|c|c|c|c|c|}
\hline & \multicolumn{2}{|c|}{ NATIONAL } & \multicolumn{2}{|c|}{ BOGOTA } \\
\hline & Coeff. & $\mathrm{t}$ & Coeff. & $\mathrm{t}$ \\
\hline $\begin{array}{l}\text { Self-reported health status } \\
\text { Fair }\end{array}$ & & & -1.539 & $-3.07 * * *$ \\
\hline Good & 0.521 & $2.31 * *$ & -1.691 & $-3.39 * * *$ \\
\hline Very Good & & & -4.190 & $-4.52 * * *$ \\
\hline Wald test & & & $7.43 * * *$ & \\
\hline Chronic disease & 0.589 & $2.08 * *$ & & \\
\hline Age-gender categories & & & & \\
\hline 1-4 & 0.352 & 0.56 & & \\
\hline $5-14$ & 0.556 & 0.96 & & \\
\hline 15-44 male & 1.024 & $1.74 *$ & & \\
\hline $15-44$ female & 1.266 & $2.3^{* *}$ & & \\
\hline $45-59$ & 0.991 & 1.63 & & \\
\hline $60+$ & 0.835 & 1.28 & & \\
\hline Wald test & $2.01 *$ & & & \\
\hline Log income per-capita & -0.404 & $-2.31 * *$ & -0.398 & -1.62 \\
\hline Constant & 3.199 & 1.55 & 5.938 & $1.88 * *$ \\
\hline $\mathrm{N}$ & 893 & & 463 & \\
\hline General Wald test & $2.57 * * *$ & & $5.66^{* * *}$ & \\
\hline
\end{tabular}

${ }^{*} p<0.1{ }^{* \star} p<0.05^{* * *} p<0.01$ 
Table 5. Log-linear regression coefficients for any OOP $>0$ among SHI enrollees.

\begin{tabular}{|c|c|c|c|c|}
\hline & \multicolumn{2}{|c|}{ NATIONAL } & \multicolumn{2}{|c|}{ BOGOTA } \\
\hline & Coeff. & $\mathrm{t}$ & Coeff. & $\mathrm{t}$ \\
\hline Chronic disease & 0.330 & $2.38^{* *}$ & & \\
\hline Age & 0.011 & $3.97 * * *$ & & \\
\hline Age-gender categories & & & & \\
\hline $1-4$ & & & 1.093 & $2.67 * * *$ \\
\hline $5-14$ & & & 0.720 & $2.15^{* *}$ \\
\hline 15-44 male & & & 0.774 & $1.98 * *$ \\
\hline 15-44 female & & & 0.913 & $2.95 * * *$ \\
\hline $45-59$ & & & 0.525 & 1.61 \\
\hline $60+$ & & & 0.873 & $2.6^{* *}$ \\
\hline Wald test & & & $2.02 *$ & \\
\hline Log income per-capita & 0.578 & $5.52 * * *$ & 0.679 & $4.72 * * *$ \\
\hline \# household members & 0.063 & $2.09 * *$ & & \\
\hline Rural & 0.238 & $1.84 *$ & & \\
\hline Region & & & & \\
\hline Oriental & 0.678 & $2.85^{* * *}$ & & \\
\hline Central & 0.362 & 1.33 & & \\
\hline Pacífico & 0.460 & $2.22^{* *}$ & & \\
\hline Bogotá & 0.680 & $3.01^{* * *}$ & & \\
\hline Antioquia & 0.287 & 1.34 & & \\
\hline Valle & 0.296 & 0.96 & & \\
\hline San Andrés & 1.552 & $2.99 * * *$ & & \\
\hline Orinoquia & 0.662 & $1.98^{* *}$ & & \\
\hline Wald test de Wald & $2.20 * *$ & & & \\
\hline Constant & 3.298 & $2.52 * *$ & & \\
\hline $\mathrm{N}$ & 1072 & & 301 & \\
\hline General Wald test & $7.90 * * *$ & & $5.47 * * *$ & \\
\hline
\end{tabular}

${ }^{*} p<0.1{ }^{* *} p<0.05^{* * *} p<0.01$ 
Table 6. Log-linear regression coefficients for any OOP $>0$ among poor uninsured

\begin{tabular}{|c|c|c|c|c|}
\hline & \multicolumn{2}{|c|}{ NATIONAL } & \multicolumn{2}{|c|}{ BOGOTA } \\
\hline & Coeff. & $\mathrm{t}$ & Coeff. & $\mathrm{t}$ \\
\hline Self-reported health status & & & & \\
\hline Fair & -0.754 & $-2.61 * * *$ & & \\
\hline Good & -0.693 & $-2.44 * *$ & -0.373 & $-2.02 * *$ \\
\hline Very Good & -0.274 & -0.9 & & \\
\hline Wald test & $4.25^{* * *}$ & & & \\
\hline Log income per-capita & 0.647 & $4.25^{* * *}$ & 0.520 & $2.66 * * *$ \\
\hline Education & & & & \\
\hline Primary & & & 0.790 & $2.8^{* * *}$ \\
\hline Secondary & & & 1.320 & $9.12^{* * *}$ \\
\hline Post-secondary & & & 1.510 & $5.24 * * *$ \\
\hline Wald test & & & $30.84^{* *}$ & \\
\hline \# Household members & 0.071 & $1.89 *$ & & \\
\hline Rural & 0.533 & $2 * *$ & & \\
\hline Constant & 4.417 & $2.39 * *$ & 4.532 & $1.93^{*}$ \\
\hline $\mathrm{N}$ & 531 & & 264 & \\
\hline General Wald test & $4.76^{* * *}$ & & & \\
\hline
\end{tabular}

${ }^{*} p<0.1{ }^{* *} p<0.05^{* * *} p<0.01$ 
Table 7. Log-linear regression coefficients for inpatient OOP $>0$ among SHI enrollees.

\begin{tabular}{|c|c|c|c|c|}
\hline & \multicolumn{2}{|c|}{ NATIONAL } & \multicolumn{2}{|c|}{ BOGOTA } \\
\hline & Coeff. & $\mathrm{t}$ & Coeff. & $\mathrm{t}$ \\
\hline \begin{tabular}{|l|} 
Self-reported health status \\
\end{tabular} & & & & \\
\hline Fair & -0.101 & -0.46 & -0.116 & -0.45 \\
\hline Good & -0.545 & $-2.07 * *$ & -0.816 & $-3.1 * * *$ \\
\hline Very Good & -0.878 & $-2.47 * *$ & -0.261 & -0.61 \\
\hline Wald test & $3.42 * *$ & & $5.82 * * *$ & \\
\hline Chronic disease & 0.419 & $2.19 * *$ & & \\
\hline Age & 0.010 & $2.66 * * *$ & & \\
\hline Gender & & & -0.341 & $-1.81 *$ \\
\hline Log income per-capita & 0.401 & $2.95^{* * *}$ & 0.522 & $2.92 * * *$ \\
\hline \# household members & 0.101 & $3.28 * * *$ & & \\
\hline Education & & & & \\
\hline Primary & & & 1.277 & $3.68 * * *$ \\
\hline Secondary & & & 1.153 & $3.52 * * *$ \\
\hline Post-secondary & & & 0.703 & $1.75^{*}$ \\
\hline Wald test & & & $6.00 * * *$ & \\
\hline Rural & 0.466 & $2.75 * * *$ & & \\
\hline Region & & & & \\
\hline Oriental & 0.360 & 1.34 & & \\
\hline Central & 0.312 & 1.15 & & \\
\hline Pacífico & 0.364 & 1.34 & & \\
\hline Bogotá & 0.673 & $2.82 * * *$ & & \\
\hline Antioquia & 0.128 & 0.43 & & \\
\hline Valle & -0.365 & -1.16 & & \\
\hline San Andrés & 0.182 & 0.32 & & \\
\hline Orinoquia & 0.362 & 1.1 & & \\
\hline Wald test & $2.52 * *$ & & & \\
\hline Local area & & & & \\
\hline Chapinero & & & 2.721 & $3.19 * * *$ \\
\hline Santa Fe & & & 1.656 & $2.43 * *$ \\
\hline San Cristóbal & & & 1.971 & $2.76^{* * *}$ \\
\hline Usme & & & 1.494 & $2.11^{* *}$ \\
\hline Tunjuelito & & & 1.234 & $1.72 *$ \\
\hline Bosa & & & 2.043 & $2.73^{* * *}$ \\
\hline Kennedy & & & 2.451 & $3.2^{* * *}$ \\
\hline Fontibon & & & 2.191 & $2.85^{* * *}$ \\
\hline Engativa & & & 1.719 & $2.42 * *$ \\
\hline Suba & & & 2.125 & $2.48^{* *}$ \\
\hline Barrios Unidos & & & 2.798 & $3.31 * * *$ \\
\hline Teusaquillo & & & 2.148 & $3.02 * * *$ \\
\hline Martires & & & 2.052 & $2.75^{* * *}$ \\
\hline
\end{tabular}




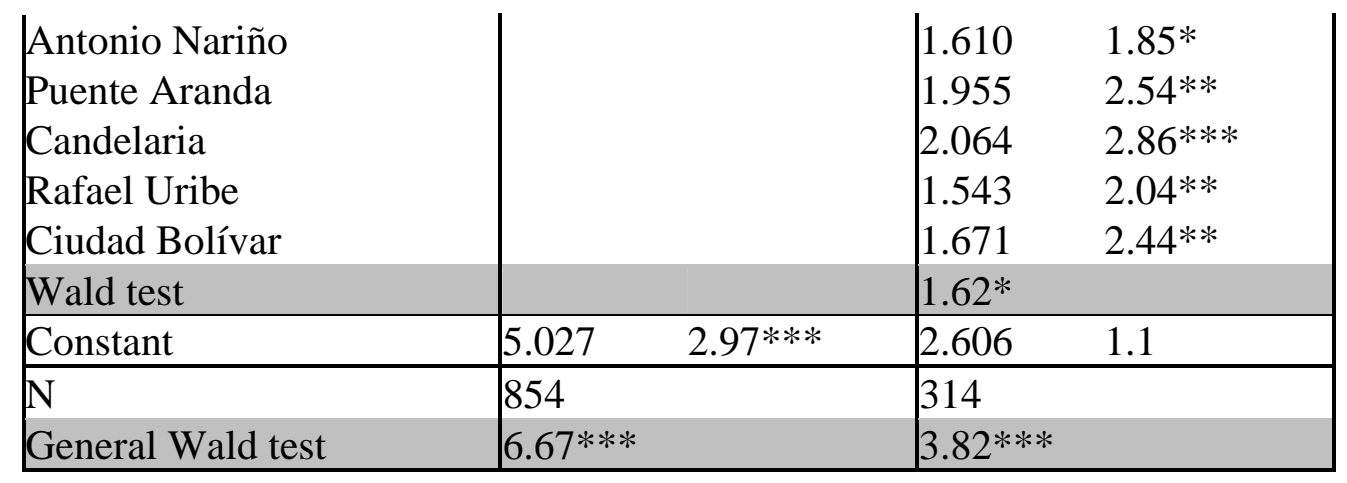

${ }^{*} p<0.1{ }^{* *} p<0.05^{* \star *} p<0.01$ 
Table 8. Log-linear regression coefficients for inpatient OOP $>0$ among poor-uninsured.

\begin{tabular}{|c|c|c|c|c|}
\hline & \multicolumn{2}{|c|}{ NATIONAL } & \multicolumn{2}{|c|}{ BOGOTA } \\
\hline & Coeff. & $\mathrm{t}$ & Coeff. & $\mathrm{t}$ \\
\hline Self-reported health status & & & & \\
\hline Fair & -0.882 & $-2.32 * *$ & -0.375 & $-1.76 *$ \\
\hline Good & -1.221 & $-3.06 * * *$ & & \\
\hline Very Good & -1.541 & $-3.29 * * *$ & & \\
\hline Wald test & $4.00^{* *}$ & & & \\
\hline Age-gender categories & & & & \\
\hline $1-4$ & 1.282 & $1.86 *$ & & \\
\hline 5-14 & 0.610 & 0.85 & & \\
\hline 15-44 male & 0.512 & 0.72 & & \\
\hline $15-44$ female & 0.627 & 0.92 & & \\
\hline $45-59$ & 1.272 & $1.83^{*}$ & & \\
\hline $60+$ & 0.842 & 1.1 & & \\
\hline Wald test & $2.46^{* *}$ & & & \\
\hline Gender & & & -0.664 & $-3.02 * * *$ \\
\hline Log income per-capita & 0.695 & $3.42 * * *$ & 0.495 & $2.67 * * *$ \\
\hline \# household members & 0.186 & $2.44 * *$ & & \\
\hline Region & & & & \\
\hline Oriental & 0.237 & 0.63 & & \\
\hline Central & 0.380 & 1.06 & & \\
\hline Pacífico & 0.373 & 0.88 & & \\
\hline Bogotá & 0.232 & 0.81 & & \\
\hline Antioquia & -0.477 & -1.25 & & \\
\hline Valle & 0.379 & 1.07 & & \\
\hline San Andrés & 1.042 & $3.05^{* * *}$ & & \\
\hline Orinoquia & 0.058 & 0.15 & & \\
\hline Wald test & $2.20 * *$ & & & \\
\hline Constant & 5.027 & 2.606 & 6.309 & $2.82 * * *$ \\
\hline $\mathrm{N}$ & 362 & & 199 & \\
\hline General Wald test & & & $6.78^{* * *}$ & \\
\hline
\end{tabular}

${ }^{*} p<0.1{ }^{* \star} p<0.05^{* \star *} p<0.01$ 
Graph 1. Expected and recycled OOP expenses for any health-care-related costs.

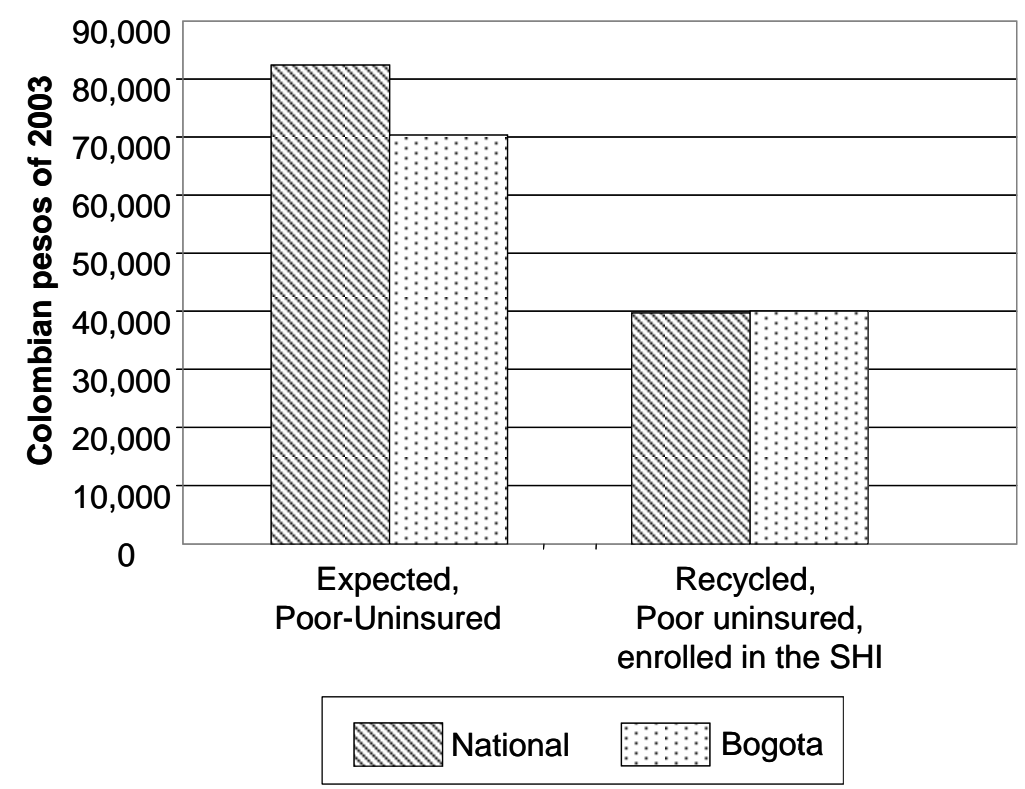

